\title{
The Impact of Emotional Intelligence on Accuracy of Self - awareness and Leadership Performance
}

\section{Authors: Virginia K. Bratton, Nancy G. Dodd, and F. William Brown}

This is a postprint of an article that originally appeared in Leadership \& Organization

Development Journal on March 8, 2011. http://dx.doi.org/10.1108/01437731111112971

Bratton, Virginia K., Nancy G. Dodd, and F. William Brown. "The Impact of Emotional Intelligence on Accuracy of Self - awareness and Leadership Performance." Leadership \& Organization Development Journal 32, no. 2 (March 8, 2011): 127-149. doi:10.1108/01437731111112971.

Made available through Montana State University's $\underline{\text { ScholarWorks }}$ scholarworks. montana.edu 


\title{
The impact of emotional intelligence on accuracy of self-awareness and leadership performance
}

\author{
Virginia K. Bratton, Nancy G. Dodd and F. William Brown \\ College of Business, Montana State University, Bozeman, Montana, USA
}

\begin{abstract}
Purpose - This research paper aims to follow a line of research that examines the impact of elements of emotional intelligence (EI), particularly those related to self-awareness, on self-other agreement and performance.

Design/methodology/approach - This is a quantitative study that employs the same methodology as Sosik and Megerian to analyze survey data gathered from a matched sample of 146 managers and 1,314 subordinates at a large international technology company based in North America.

Findings - The analysis revealed that the relationship between EI and leader performance is strongest for managers who underestimate their leader abilities. Underestimators earn higher follower ratings of leader performance than all other agreement categories (In agreement/good, In agreement/poor, and Overestimators). The analysis also suggests that there appears to be a negative relationship between $\mathrm{EI}$ and leader performance for managers who overestimate their leader abilities.

Research limitations/implications - Implications of the counterintuitive findings for underestimators as well as the imperative for further study utilizing alternative measures of EI are discussed.

Originality/value - Previous empirical work in this area used an ad hoc measure of EI. This study extends this work by utilizing a larger, business sample and employing a widely-used and validated measure of EI, the Emotional Quotient Inventory. Results further illuminate the nature of the relationship between EI and self-other agreement and provide a potential selection and development tool for the improvement of leadership performance.
\end{abstract}

Keywords Emotional intelligence, Transformational leadership, Self assessment, Leadership, Management effectiveness

Paper type Research paper

\section{Introduction}

The interest in the nature and determinants of social influence and leadership capacity can be traced in history as far back as 2300 BC (Bass, 1990; Bryman, 1996; Grimal, 1992). Possibly the most significant event in contemporary leadership theory development was the publication of Burns' (1978) narrative account of the nature of transactional and transformational leadership in large-scale political systems. This characterization of leadership particularly attracted the attention of Bass and his colleagues, who developed and evaluated a comprehensive "full range" model of leadership emphasizing the efficacy of transformational leadership (e.g. Bass, 1985a, b, 1990, 1999; Bass and Avolio, 1990). The positive relationship between transformational 
leadership and desired organizational and individual outcomes has been consistently affirmed in a wide variety of individual and meta-analytic studies (e.g. Bass, 1999; Judge and Piccolo, 2004; Lowe et al., 1996) and represents one of the most examined relationships in the organizational behavior domain (George, 2000). Less clear, however, are the dispositional and intervening mechanisms that impact this relationship. Recent attention has been drawn to emotional intelligence (EI) and self-awareness in the hope that they might help to further clarify the relationship between leader performance and organizational outcomes (Yammarino and Atwater, 1997; Sosik and Megerian, 1999). Yet, to date these studies have yielded contradictory and counter-intuitive findings. One explanation may lie in the empirical limitations of this work (Antonakis et al., 2009). Before we can make recommendations to business practitioners about the value and contributions of EI to leader effectiveness and organizational performance, we need to address these empirical limitations.

The current study follows a line of research which examines the impact of elements of EI, related to self-awareness, on self-other agreement and leader performance, and seeks to clarify past results through empirical improvements. We follow the theory of Yammarino and Atwater (1997) while utilizing the methodological approach of Sosik and Megerian (1999). However, where Sosik and Megerian (1999) employed an ad hoc measure of EI, we utilize the Emotional Quotient Inventory (EQI) (Bar-On, 1997). Further, we extend the research of Sosik and Megerian by testing it on a large sample in a non-military, manufacturing research setting.

\section{Literature review}

\section{EI}

The existence and potential importance of forms of intelligence other than memory and problem solving have long been recognized, most notably by some of those most closely associated with establishing the contemporary understanding of cognitive intelligence (Piaget, 1981; Thorndyke and Stein, 1937; Wechsler, 1940). However, it was the work of Goleman (1995) and its emphasis on the potential benefits of EI, which caught the attention of practitioners and management researchers.

In the last two decades the interest in EI has been simultaneously intense and controversial. Essentially, two distinct formulations of EI have emerged: an ability model and a mixed model. The ability model, most closely associated with the work of Mayer and Salovey (1993), actually predates Goleman's (1995) work and is an empirically derived combination of emotion and intelligence. Mayer and Salovey (1993, p. 434) define EI as the "ability to advantageously deal with one's own emotions and those of others in problem solving and decision making". The key dimensions of an ability model are generally described as: the ability to monitor one's own and others' feelings and emotions; to discriminate among those emotional states; and to use this information to effectively guide one's thinking and action (Salovey and Mayer, 1990).

The mixed model of EI, as advocated by Goleman $(1995,1998)$, combines traits with social behaviors and competencies. Bar-On (1997, p. 122), usually associated with the mixed model of EI, concluded that emotional and social intelligence are a "multifactorial array of interrelated emotional, personal, and social abilities that influence individual ability to actively and effectively cope with daily demands and pressures". Bar-On's (1997) conceptualization is reflected in his EQI, an assessment 
instrument extensively used to measure the mixed model of EI. In the EQI, the elements of a mixed model of EI are measured through scales which assess awareness of individual emotional states, interpersonal skills, adaptability, the ability to handle stress and general mood (Bar-On, 1997).

The mixed model has been both advocated and criticized. Support typically centers on contentions of a correlation between mixed model EI and desired organizational outcomes (Goleman, 1995, 1998; Goleman et al., 2002). Criticisms of the mixed model have tended to focus on a lack of scientific rigor in model development (Conte, 2005; Landy, 2005; Mayer et al., 2008), a lack of content validity (Antonakis et al., 2009; Mayer et al., 2008), or overstatements regarding benefits (Ashkanasy and Daus, 2005; Grubb and McDaniel, 2007). Nevertheless, mixed models in general, and the EQI in particular, continue to be very widely utilized in organizational development and practitioner settings. In fact, the EQI has been found to be a key predictor of job performance (Bachman et al., 2000) with stronger support than either cognitive ability (Jae, 1997) or academic achievement (Parker et al., 2004) in determining job performance. Despite their differences, both the mixed and ability models posit a positive relationship between non-cognitive capabilities and desired interpersonal and organizational outcomes (e.g. Goleman et al., 2002; Wong and Law, 2002; Mayer and Salovey, 1997).

While practitioners have found the notion of EI intuitively satisfying and compelling, vigorous disputes have arisen in the academic literature regarding a number of aspects of EI. There is debate over the very existence of EI (Antonakis $e$ t al., 2009; Landy, 2005; Locke, 2005), how it is measured (Conte, 2005), and criticism/advocacy for particular models of EI (Ciarrochi et al., 2000; Daus and Ashkanasy, 2005; Mayer et al., 2008; Mayer et al., 2000). Despite this considerable attention, matters of common definition, measurement and the nature of the relationship between EI and desired outcomes have not been conclusively resolved (Brown and Moshavi, 2005). Recent studies and reviews suggest movement toward a resolution of long-standing definition, measurement and application issues and support the potential value of EI to organizational behavior (e.g. Cote and Miners, 2006; Gowing et al., 2006; Mayer et al., 2008).

\section{Self-other agreement}

Because of biases in self-ratings (Podsakoff and Organ, 1986), researchers and practitioners have looked closely at self-appraisals to examine the degree of agreement between self and other evaluations. An implicit assumption that has underpinned the ubiquity of 360-degree feedback programs has been the proposition that an accurate self-perception can enhance leadership performance. Although research has shown that self-awareness does not always lead to performance gains in negotiation situations (Der Foo et al., 2004), there is a well-established body of research which generally affirms the contention that self-awareness has a positive impact on leadership performance (e.g. Ashford, 1989; Atwater and Yammarino, 1992; Kluger and DeNisi, 1996; Sosik, 2001; Wegner and Vallacher, 1980; Wicklund, 1979). Generally, these studies have held that individual self-awareness is positively associated with desired affective outcomes and increased managerial effectiveness. Agreement between self and others is seen as leader self-awareness, and is important because self-aware leaders can change their behavior to adjust for subordinate perceptions toward the goal of 
increasing overall leader effectiveness. A recent line of research has further explored and underscored the importance of this connection between self-awareness and leader effectiveness through the lens of authentic leadership and followership (Gardner et al., 2005; Luthans and Avolio, 2003). Specifically, leader self-awareness has been linked to higher levels of follower trust and organizational commitment (Sosik, 2001), mentoring behavior (Sosik et al., 2004), the use of influence tactics (Berson and Sosik, 2007), impression management (Sosik and Jung, 2003), and performance (e.g., Atwater and Yammarino, 1992; Atwater et al., 1998; Moshavi et al., 2003; Young and Dulewicz, 2007).

In previous research (e.g., Yammarino and Atwater, 1997; Cogliser et al., 2009), managers who are self-aware are categorized as in agreement, which can be divided further into in agreement/good and in agreement/poor. The in agreement/good category denotes self-ratings of supervisors and ratings by subordinates that are both positive regarding the leadership behavior and in agreement. The in agreement/poor category represents self-ratings of supervisors and ratings by subordinates that are both low and in agreement (Yammarino and Atwater, 1997). Managers whose self-ratings are below those of subordinates are categorized as underestimators, whereas managers who rate themselves as higher than their subordinates are categorized as overestimators. Thus far, research (Atwater et al., 1998; Yammarino and Atwater, 1997) has suggested that more positive behavioral and affective results tend to be associated with underestimators and those in agreement. Overestimators are often described as having negative attitudes, misperceiving their strengths and weaknesses, and lacking awareness of the need for training and development (Yammarino and Atwater, 1997). However, other research results have yielded somewhat counter-intuitive findings (Moshavi et al., 2003; Godshalk and Sosik, 2000; Sosik and Godshalk, 2004; Sosik and Megerian, 1999) concerning the perceived managerial/leadership effectiveness of underestimators. Although, theory would suggest that those in agreement would have a better grasp of capabilities and thus manage more effectively, study results reveal that underestimators tend to garner higher leader assessments from their followers.

Like virtually everything else in organizational behavior, the relationship between an accurate self-perception and performance is not that simple - possibly because it relies greatly on the social context of the feedback received (Levy and Williams, 2004). As an example, sometimes 360 degree or upward feedback does not result in performance improvement (Atwater et al., 2000; Johnson and Ferstl, 1999). Research has indicated that managers may choose to ignore the feedback received by subordinates if it is perceived that this feedback is inaccurate, unfair, or much lower than expected (Brett and Atwater, 2001; Facteau and Facteau, 1998; Ilgen et al., 1979; Waldman and Bowen, 1998). An important variable in ensuring the proper use of subordinate feedback may lie in the EI of managers.

\section{Transformational leadership}

Much of the self-other agreement research has focused on the extent to which managers and subordinates agree on the level of charismatic or transformational leadership behaviors exhibited by the manager. In this study, we also focus on transformational leadership, as it is a well-accepted and widely studied concept (e.g., Bass, 1990) that has been used in a variety of settings. Effective managerial strategies, 
such as impression management (Sosik and Jung, 2003), influence tactics (Berson and Sosik, 2007), mentoring (Sosik et al., 2004), and building subordinate trust and organizational commitment (Sosik, 2001), as well as managerial (Atwater et al., 1998) and subordinate performance (Moshavi et al., 2003) have also been associated with supervisor-subordinate agreement regarding transformational or charismatic leadership. In each case, underestimators were found to be associated with more positive outcomes than overestimators.

Sosik and colleagues (Sosik and Megerian, 1999; Sosik and Godshalk, 2004) suggested that overestimators may be perceived as being insincere and self-absorbed, while not recognizing their weaknesses. They may have hostile and resentful attitudes and not see the need for personal development (Yammarino and Atwater, 1997). These characteristics can easily lead to negative outcomes for subordinates and result in low evaluations of transformational leadership for managers who overestimate their abilities.

EI has long been theorized to contribute to effectiveness in leadership (Antonakis et al., 2009; Dasborough, 2006; George, 2000), and transformational leadership in particular. However, empirical work demonstrating this link is less conclusive. Perhaps the key lies in clarifying the mechanism through which EI impacts leadership. The answer may lie in the relationship between EI and self-awareness of leadership effectiveness.

\section{Self-other agreement, leadership, and EI}

In addition to examining relationships between managerial strategies or performance and agreement categories, researchers are interested in other variables that might be associated with self-other agreement. The emotional self-awareness aspect of EI makes it a key variable in self-other agreement research and the theory of self-awareness in leadership success (Gardner et al., 2005). The primary question in these studies is: does the emotional self-awareness aspect of EI have a positive relationship with a manager's awareness of leadership skills? Sosik and Megerian (1999) looked at the relationship between EI and transformational leadership based on whether leaders were in agreement or not in agreement. They found that for leaders who were in agreement, subordinate evaluations of transformational leadership were positively related to EI. They suggested that self-aware managers (those in agreement) had higher EI and were considered to be more effective by both superiors and subordinates. They also found that one aspect of EI, social self-confidence, was positively related to ratings of transformational leadership for underestimators, while subordinate ratings of transformational leadership were negatively related to another aspect of EI, sensitivity, for overestimators (Sosik and Megerian, 1999).

This study follows the theoretical approach of Atwater and Yammarino (1997) and the methodological approach of Sosik and Megerian (1999) to extend the use of empirical methods to examine the influence of individual and personality characteristics on self-other rating comparisons. Sosik and Megerian (1999) examined the relationship between self-awareness, measured by 63 self and 192 follower assessments of leader transformational leadership behaviors, and elements of EI, assessed by an ad hoc measurement instrument. Their study provided evidence in support of the contention that EI could be a useful dispositional factor in identifying effective management candidates. However these findings are limited by Sosik and Megerian's (1999) 
operationalization of EI with an untested, unvalidated measure. The present study extends the previous work by utilizing a larger business sample, a validated and widely-used measure ofEI(theEQI) and essentially the same methodology to replicate the Sosik and Megerian (1999) study. Results further illuminate the nature of the relationship between EI and self-other agreement and provide a potential selection and development tool for the improvement of leadership performance.

\section{Hypotheses}

In their research, Sosik and Megerian (1999) used an ad hoc measure of EI, derived from a number of different scales: private self-consciousness, public self-consciousness, purpose-in-life, self-monitoring, personal efficacy, interpersonal control, social self-confidence, even-temperedness, and sensitivity. As stated previously, the current study replicates and extends the work of Sosik and Megerian by using Bar-On's (1997) EQI, in particular the intrapersonal, interpersonal, and adaptability subscales which address elements of awareness, control and behavioral motivation.

Past research (Atwater and Yammarino, 1992; Yammarino and Atwater, 1997) maintains that self-aware employees tend to be successful, strong performers with positive job attitudes. Furthermore, Atwater and colleagues (Atwater and Yammarino, 1992; Atwater et al., 1998) assert leaders who are in agreement are more effective. These claims are supported by Church (1997), who found that accurate self-assessors account for the greatest number of high performers (over under- and over-estimators). It is reasonable to expect that these high-performing leaders, who are accurate self-assessors, have been able to capitalize on inherently high levels of EI. Specifically, through their ability to accurately gauge their leader performance, self-assessors are presumed to be self-aware, able to interact effectively with others, and able to adapt to the situation as required. This last caveat, adaptability, implies that these leaders are in agreement with follower assessment of strong leadership ability or in agreement/good.

The self-awareness or private self-consciousness (Atwater and Yammarino, 1997; Sosik and Megerian, 1999) component of EI will result in accuracy in self-perception of leadership skill (Van Velsor et al., 1993). In agreement/good individuals further possess an interpersonal orientation (Atwater and Yammarino, 1997; Sosik and Megerian, 1999) that is consistent with high EI. Finally, in agreement/good individuals possess internal loci of control (Atwater and Yammarino, 1997; Sosik and Megerian, 1999) that is indicative of the adaptability component of EI (Salovey and Mayer, 1990; Sosik and Megerian, 1999), particularly in the realm of transformational leadership (Bass, 1985a; Burns, 1978; Ross and Offermann, 1997). Thus we predict that there will be a strong positive relationship between EI and transformational leadership for individuals who accurately and positively assess their leader abilities, as reflected in the following hypothesis:

H1. EI, as measured by the EQI, will be positively related to transformational leader behavior for those who are in agreement/good.

As emphasized by Atwater and Yammarino (1997), in order to better understand the performance of self-raters, it is necessary to examine both the magnitude and the direction of the difference in self-other ratings. We expect that managers who have high levels of EI will be more likely to realistically assess their performance in terms of 
transformational leadership and thus be in stronger agreement with subordinate assessments even if both parties agree that these leadership skills could improve. Drawing on research that equates EI with self-awareness (Shipper et al., 2003), we predict that managers who are in agreement/poor will hold high levels of EI in the areas of intrapersonal awareness and interpersonal skill as these individuals can accurately assess their personal leadership performance and the perceptions of their followers. However, we expect that these managers will possess slightly lower levels of EI than those who are in agreement/good as they will tend to be deficient in the EI component of adaptability:

H2. EI, as measured by the EQI, will be positively related to transformational leadership for those who are in agreement/poor.

Some studies (Atwater and Yammarino, 1997; Sosik and Megerian, 1999) have hypothesized that managers who overestimate their leadership ability possess some components of $\mathrm{EI}$ in that the public-self consciousness of leaders, which can be linked to El's self-awareness, can bring about inflated self-ratings. However, in more recent work (Sosik, 2001; Sosik and Godshalk, 2004) overestimators have been found to underperform in the area of leadership. This may be because overestimators often ignore negative feedback from their followers that is inconsistent with self-evaluations, which prevents improvement particularly in the area of leadership (Atwater and Yammarino, 1997). This suggests that overestimators are deficient in EI, specifically in the areas of intrapersonal awareness (indicated by the tendency to overestimate leadership capability), interpersonal skill (indicated by the tendency to ignore feedback inconsistent with self-evaluations), and adaptability (indicated by the resultant tendency to leave leadership shortcomings unaddressed). In other words, managers who have lower levels of EI will be less likely to perceive dissatisfaction among subordinates in their leadership performance and will overestimate their skills in transformational leadership. Thus, we expect there to be a positive relationship between EI and transformational leadership such that low levels of EI in overestimators will result in correspondingly low levels of transformational leadership:

H3. EI, as measured by the EQI, will be positively related to transformational leadership for those who are overestimators.

It is intuitive to presume that managers who underestimate their transformational leadership abilities are lacking in the intrapersonal, or self-awareness, component of EI (Atwater and Yammarino, 1997; Godshalk and Sosik, 2000; Sosik and Megerian, 1999). However underestimators consistently have been found to outperform all other categories of agreement as leaders (Moshavi et al., 2003; Sosik and Megerian, 1999) as well as mentors (Godshalk and Sosik, 2000; Sosik and Godshalk, 2004). Although underestimators may lack self-awareness, research indicates that they are able to effectively operate at an interpersonal level (Sosik and Godshalk, 2004) and adapt their behaviors to perform at a high level (Atwater et al., 1998). Underestimators may be better able to mentor because of their critical self-evaluation, humility, and willingness to put others ahead of themselves for the general good (Godshalk and Sosik, 2000). This is consistent with the leadership literature that asserts high performers are modest and humble and relates to the altruistic component of transformational 
leadership (Kanungo and Mendonca, 1996). Thus, we predict that there will be a positive relationship between EI (particularly the components of interpersonal skill and adaptability) and transformational leadership for underestimators:

H4. EI, as measured by the EQI, will be positively related to transformational leadership for those who are underestimators.

\section{Method}

Setting and subjects

Data for the current study were collected as a part of the management development program at the North American manufacturing unit of a large international technology company. Utilizing Avolio and Bass's (1995) Multifactor Leadership Questionnaire (MLQ) and as a part of the management development process, 146 managers and supervisors completed the self rating (regarding their own perceptions of the degree to which they engaged in certain leadership behaviors) and other rating (regarding their perceptions of the degree to which their own managers engaged in certain leadership behaviors) versions. These 146 participants also completed the EQI at one of these sessions. At each session the general manager of the plant encouraged authentic responses, provided assurances about anonymity and emphasized the developmental, non-evaluative objectives of the program. Separate data collection sessions were held for all hourly employees and non-supervisory members of the administrative and professional staffs. At these sessions participants were asked to complete the MLQ-other in regard to their perceptions of the degree to which their managers or supervisors engaged in certain leadership behaviors. In each session, a member of the senior management team explained that all managers at the facility were participating in a development program, encouraged authentic responses and provided assurances regarding anonymity.

A total of 1,314 individuals provided useable responses regarding the leadership behaviors of 146 managers who had also completed the self report version of the MLQ and the EQI. Only managers who had a minimum of three follower responses were included in the current study. The 146 managers included in the study had an average of 14.42 years of longevity in the company and 5.34 years in their current jobs. Of the respondents, 73 percent (107) identified themselves as male and 27 percent as female.

\section{Leadership measures}

The MLQ was developed by Bass and Avolio (1990) to measure the behaviors associated with transformational leadership. The MLQ has been shown to have reliability (Bass and Avolio, 1990; Lowe et al., 1996). In this study the rater and leaders (self) Form 5x of MLQ (Bass and Avolio, 1990) was utilized. The scale of interest in this study is an overall assessment of transformational leadership (reliability coefficient of 0.90) which was produced by summing the four subscales of transformational leadership (individual attention, intellectual stimulation, inspirational motivation, and idealized influence) measured in the MLQ. This provided a self-assessment of transformational leadership for each of the 146 manager/supervisors, which could be compared to the aggregated rater assessments for each of the 1,314 hourly workers who reported to one of those supervisors (reliability coefficient of 0.94). Each of the manager/supervisors in the study had from three to 30 individuals reporting directly to 
him or her $($ mean $=9.0, \mathrm{SD}=6.7)$. The subordinates' assessments of the transformational leadership behaviors of their supervisors were averaged to provide a basis for comparison between self and follower assessments at the group level of analysis. To examine the appropriateness of this data aggregation, within group agreement indices were calculated utilizing a procedure described by James et al. (1984). James et al. (1984) describe a procedure for calculating an estimate of interrater reliability Rwg and suggested a 0.70 level as being adequate for aggregation of the data. In the current data set 83 percent of the 146 supervisory units were found to have a RWG value over 0.70, easily clearing the threshold for aggregation. Subsequent authors have suggested that there are other potential measures of interrater reliability and interrater agreement (LeBreton and Senter, 2008). Accordingly, following the approach suggested by Bliese (1998) in which intraclass correlations (ICCs) are calculated to measure the proportion of observed variance in ratings that is due to systematic between-target differences compared to the total variance in ratings. ICC(1) and ICC(2) coefficients were estimated for the follower perceptions of TL. The ICC(1) estimate was 0.21 and $\operatorname{ICC}(2)$ was estimated to be 0.80 . In the guidelines developed by LeBreton and Senter (2008) this would indicate "strong agreement" The results from both approaches strongly support the contention that aggregation is appropriate.

EI

Each of the manager/supervisors in this study also completed Bar-On's (1997) EQI. The EQI contains 133 items and produces an overall emotional quotient (EQ) score and five subscales. The five subscales are:

(1) Intrapersonal;

(2) Interpersonal;

(3) Adaptability;

(4) Stress management, and

(5) General mood.

For the purposes of this research and in keeping with our hypotheses, we focus on the Intrapersonal, Interpersonal and Adaptability subscales of the EQI. High scores on the Intrapersonal subscale indicate an individual who is in touch with her feelings and has positive feelings about herself and her life (Bar-On, 1997). High scores on the Interpersonal subscale indicate good interpersonal skills (Bar-On, 1997). High scores on the Adaptability subscale indicate an ability to cope with environmental demands and pressures (Bar-On, 1997). The EQI, widely used in management development, has been shown to have reasonable levels of reliability, validity, and psychometric independence (Bar-On, 1997; Dawda and Hart, 2000).

\section{Assignment to agreement categories}

Atwater and Yammarino (1997) initiated a line of research based on the proposition that personal and situational variables (e.g., age, gender, race, time with the manager) affect self-other rating comparisons (in this case perceptions of transformational leadership). They contend that these interactions subsequently impact individual and process variables at the organizational level (e.g., productivity, turnover). Atwater et al. 
(1998, p. 582) described the functional form of this model as "additive main effects model of self-other agreement" in which both self ratings and other ratings are believed to be related to outcomes. Such an arrangement is consistent with theoretical frameworks and venerable traditions of the study of the impact of dispositional factors on the outcomes of leaders' influence (e.g., Bono and Judge, 2004).

Given limitations in the reliability of difference scores (Edwards, 1993), in order to characterize the degree of agreement and organize the analysis of that agreement, manager/supervisors were assigned to one of four agreement groups. They were assigned to those groups according to relative differences between their self-assessments and the aggregated ratings of their subordinates. In making these assignments, we were informed by the procedure described by Atwater and Yammarino (1997). The difference between the managers' and subordinates' leadership ratings was computed, and then each manager's difference score was compared to the mean difference score. Managers whose difference scores were one-half standard deviation or more above the mean difference were assigned to the overestimator category. Managers whose difference scores were one-half standard deviation or more below the mean difference were categorized as underestimators. Managers whose difference scores were within one-half standard deviation of the mean difference and their subordinates' ratings were above the subordinate ratings grand mean were categorized as being in agreement/good. Managers whose difference scores were within one-half standard deviation of the mean difference and their subordinates' ratings were below the subordinate ratings grand mean were categorized as being in agreement/poor. Once manager/supervisors were assigned to an agreement category, the overall EQI score and each of the five EQI subscale scores for their cohort were calculated as seen in Table I.

\section{Control variables}

Two factors outside the interest of this study were included due to past research suggesting relationships with key research variables. Gender was included due to a stream of research investigating the slow advancement of women into and through managerial ranks (e.g., Cleveland et al., 2005; Duehr and Bono, 2006; Stroh et al., 1992). Thus, we sought to control for the possible negative bias of manager gender on follower ratings of leader effectiveness. Manager job tenure also was collected as a proxy measure for the length of time subordinates have known managers. Research has shown that the accuracy of subordinate feedback seems to be influenced by how long a rater has known the ratee. In manager-subordinate relationships that were older than three years, ratings tend to increase and be based more on affect and affinity than on performance (Eichinger and Lombardo, 2004). Thus, we incorporated this variable to control for the possible positive bias of tenure-based affinity on follower ratings of leader effectiveness.

\section{Results}

Means, standard deviations and correlations of the key variables of interest are reported in Table II. For each category of agreement, a one-way analysis of variance (ANOVA) was employed to compare within group variance and between group variance. ANOVA results indicated highly significant between group variance, justifying post hoc examination of the observed mean differences. Numerous significant group differences based on level of follower-self rating agreement for 


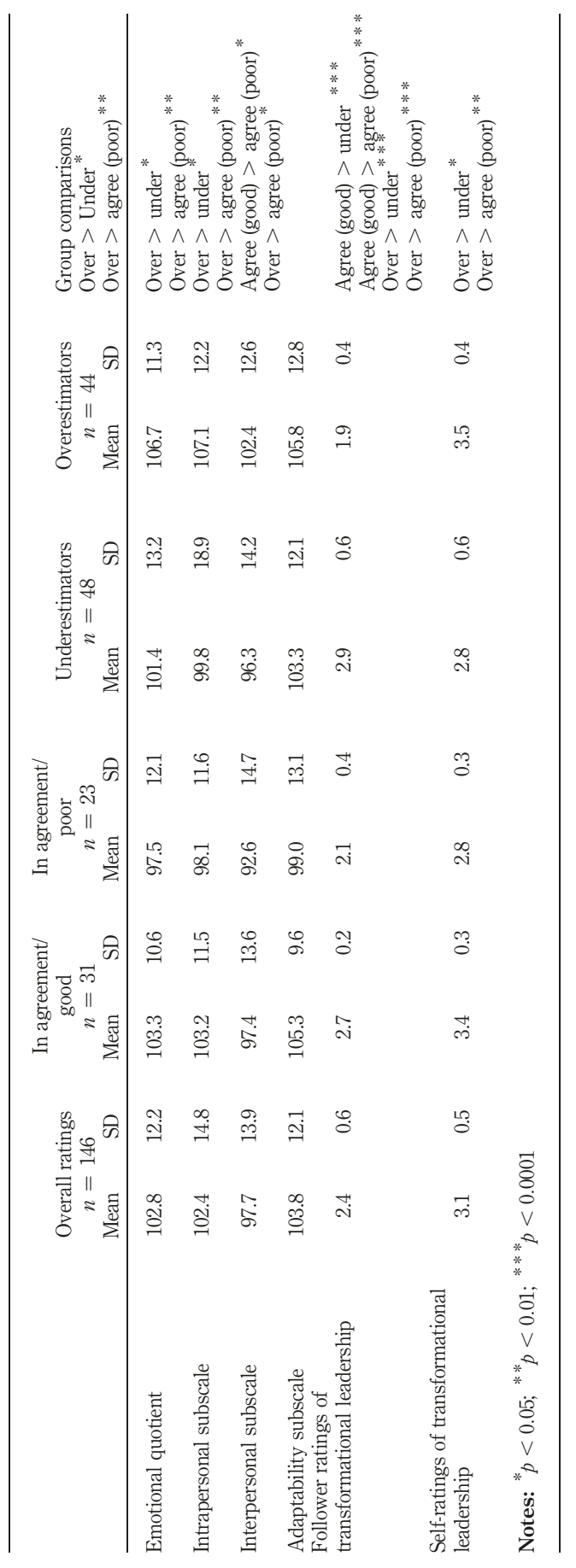

Table I. Means and standard deviations for EQI, EQI subscales and transformational leadership in self versus other agreement groups 
Table II.

Means, standard deviations, alphas and intercorrelations

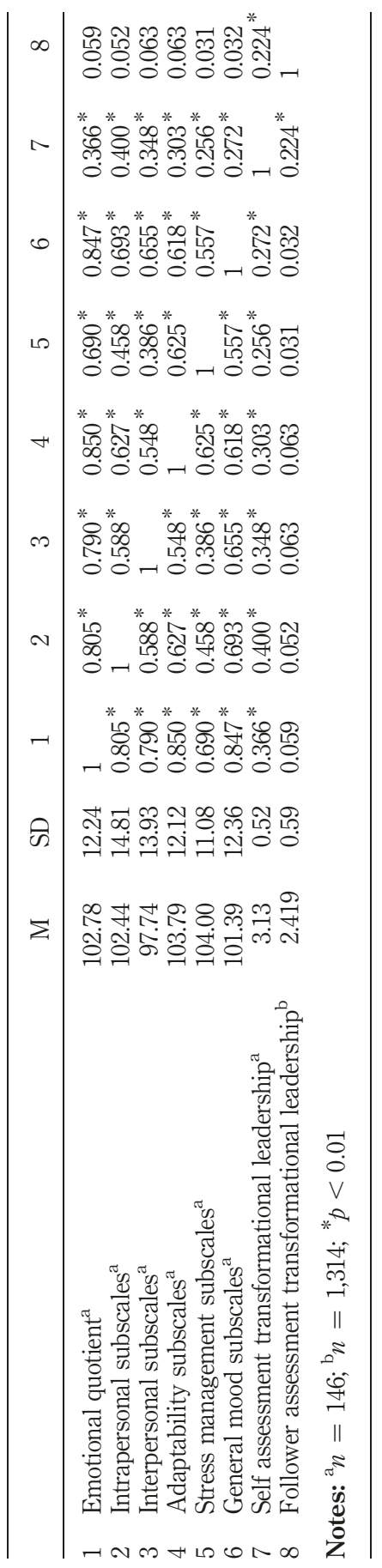


transformational leadership, utilizing Scheffe, are identified in Table I. Of particular interest are the frequent instances of significantly higher levels of EI for overestimators. On the overall EQI score, overestimators are significantly higher than underestimators or managers who are in agreement/poor. That same relationship is observed on the intrapersonal and interpersonal subscales. Overestimators are also significantly higher on the adaptability and general mood subscales than those in agreement/poor. Although there was a positive relationship observed for in agreement/good on the overall EQI score as well as its subscales, the observed relationships are not as strong or as significant as for overestimators. Similar results were observed for in agreement/poor at lower strength than that of in agreement/good.

Hypotheses were tested using multiple regression analyses. The covariates of gender and job tenure were entered on the first step and the three EI variables of interest were entered on the second step. A significant change in $R^{2}$ indicated the additional variance contributed by the variables entered in each step, and the individual betas showed which variables were significant at that step. Table III provides the results of these analyses for each agreement category. Based on the fact that EQI variables did not serve as predictors of follower assessment of leadership for in agreement/good, $H 1$ was not supported. $H 1$ posits that EI will be positively related to transformational leadership for managers who are in agreement/good. This relationship was not significant in the current study.

H2, which states that EI will be positively related to transformational leadership for managers who are in agreement/poor also was not supported. As theorized in our hypothesis development, managers who are in agreement/poor were at significantly lower levels in the adaptability EQI subscale than managers who are in agreement/good (see Group Comparisons column in Table I). However as Table III illustrates, there was no significant relationship between the EQI subscales and follower assessment of transformational leadership for managers who are in agreement/poor.

H3 states that EI in managers will be positively related to transformational leadership for managers who are overestimators. As previously noted and contrary to our prediction, Table I illustrates numerous instances in which overestimators have significantly higher EQI or subscale scores. In fact, there are no instances in which overestimators have significantly lower scores on the EQI or subscale categories thereof than any other category of agreement. However, Table III indicates that the relationships between EQI subscales and follower ratings of leadership were insignificant. Therefore, our results fail to support $H 3$.

H4 predicts that there will be a positive relationship between EI and transformational leadership behaviors for managers who are underestimators. Table I reveals that underestimators tend to have significantly higher follower ratings of transformational leadership behaviors than either overestimators or those in agreement/poor. As expected, underestimators were found to have higher scores on the EQI subscale category of adaptability as well as the overall EQI. Table III confirms that there is a strong and significant relationship between the intrapersonal subscale of $\mathrm{EQI}$ and follower ratings of leadership for underestimators $(B=0.351, p<0.05)$. Thus, $H 4$ is partially supported as there is strong evidence indicating a positive relationship between Intrapersonal skills in underestimators and subordinate ratings of their leadership effectiveness. 


\begin{tabular}{|c|c|c|c|}
\hline & $B^{1}$ & $R^{2}$ & $\Delta R^{2}$ \\
\hline \multicolumn{4}{|c|}{$\begin{array}{l}\text { Dependent variable }=\text { follower ratings of } \\
\text { transformational leadership for agree (good) }\end{array}$} \\
\hline \multicolumn{4}{|l|}{ Step 1: control variables } \\
\hline Gender & 0.100 & & \\
\hline Tenure & $0.389^{*}$ & & \\
\hline$F(2,27)=2.320, p=118$ & & 0.147 & 0.147 \\
\hline \multicolumn{4}{|c|}{$\begin{array}{l}\text { Step 2: Emotional intelligence (adaptability, } \\
\text { interpersonal, and intrapersonal subscales) }\end{array}$} \\
\hline Adaptability subscale & -0.113 & & \\
\hline Interpersonal subscale & 0.130 & & \\
\hline Intrapersonal subscale & -0.143 & & \\
\hline$F(3,41)=6.435, p=0.447$ & & 0.170 & 0.024 \\
\hline \multirow{2}{*}{\multicolumn{4}{|c|}{$\begin{array}{l}\text { Dependent variable }=\text { follower ratings of } \\
\text { transformational leadership for agree (poor) } \\
\text { Step 1: control variables }\end{array}$}} \\
\hline & & & \\
\hline Gender & 0.142 & & \\
\hline Tenure & 0.350 & & \\
\hline$F(2,20)=1.983, p=0.164$ & & 0.165 & 0.165 \\
\hline \multicolumn{4}{|c|}{$\begin{array}{l}\text { Step 2: emotional intelligence (adaptability, } \\
\text { interpersonal, and intrapersonal subscales) }\end{array}$} \\
\hline \multicolumn{4}{|l|}{ Adaptability subscale } \\
\hline \multicolumn{4}{|l|}{ Interpersonal subscale } \\
\hline \multicolumn{4}{|l|}{ Intrapersonal subscale } \\
\hline$F(3,17)=1.343, p<0.294$ & & 0.283 & 0.118 \\
\hline \multicolumn{4}{|c|}{ Dependent variable $=$ follower ratings of } \\
\hline \multicolumn{4}{|c|}{ Step 1: control variables } \\
\hline \multirow{2}{*}{\multicolumn{4}{|c|}{$\begin{array}{l}\text { Gender } \\
\text { Tenure }\end{array}$}} \\
\hline & & & \\
\hline$F(2,41)=0.865, p=0.429$ & & 0.040 & 0.040 \\
\hline \multicolumn{4}{|c|}{$\begin{array}{l}\text { Step 2: emotional intelligence (adaptability, } \\
\text { interpersonal, and intrapersonal subscales) }\end{array}$} \\
\hline Adaptability subscale & -0.084 & & \\
\hline Interpersonal subscale & 0.313 & & \\
\hline Intrapersonal subscale & -0.039 & & \\
\hline$F(3,38)=0.908, p<0.486$ & & 0.107 & 0.066 \\
\hline \multicolumn{4}{|c|}{ Dependent variable $=$ follower ratings of } \\
\hline \multicolumn{4}{|c|}{ Step 1: control variables } \\
\hline Gender & -0.010 & & \\
\hline Tenure & $0.543^{* *}$ & & \\
\hline$F(2,44)=9.137, p<0.001$ & & 0.293 & $0.293^{* *}$ \\
\hline \multicolumn{4}{|c|}{$\begin{array}{l}\text { Step 2: emotional intelligence (adaptability, } \\
\text { interpersonal, and intrapersonal subscales) }\end{array}$} \\
\hline Adaptability subscale & 0.060 & & \\
\hline Interpersonal subscale & 0.023 & & \\
\hline Intrapersonal subscale & $0.351^{*}$ & & \\
\hline$F(3,41)=6.435, p<0.001$ & & 0.440 & 0.146 \\
\hline
\end{tabular}

Table III.

Hierarchical regression results for emotional intelligence and follower assessment of underestimators
Notes: ${ }^{*} p<0.05 ;{ }^{* *} p<0.001$; standardized regression coefficients are displayed 


\section{Discussion}

The purpose of this study is to replicate and extend the findings of Sosik and Megerian (1999) by employing a validated measure of EI, the EQI, and examining its relationship with follower and self-assessments of transformational leadership. Our research indicates that there is a positive relationship between EI and follower ratings of transformational leadership for managers who are underestimators (giving partial support to $H 4$ ). Although $H 1$ and $H 2$ were not supported, Table I suggests a positive relationship between these variables for managers who are in agreement/good and in agreement/poor. Contrary to $H 3$, Table I indicated a negative relationship might exist between EI and transformational leadership for managers who overestimated their leadership skill. Employing the EQI, this research supports the findings of Sosik and Megerian (1999), highlighting the variance in the relationship between EI and leader behavior across differing categories of self-awareness (illustrated in Table I). These results will be further examined in the paragraphs that follow.

H1, which posited a positive relationship between EI and leader behavior for managers who were in agreement/good, was not supported by the regression analysis results. However, Table I exhibits mean scores for in agreement/good, illustrating high levels of EI (particularly for the interpersonal subscale) and follower ratings of leader behavior that lends partial support for the existence of this relationship in this study. This result is consistent with prior research (Atwater and Yammarino, 1997; Sosik and Megerian, 1999; Yammarino and Atwater, 1997). Furthermore, this result makes intuitive sense. We expect that good managers are self-aware and aware of their follower sentiments. Good managers know when they need to improve, and they are able to adapt their behavior to make these improvements. Skilled managers therefore exhibit high levels of intrapersonal and interpersonal awareness as well as adaptability- they possess high levels of EI and are able to leverage this EI in order to demonstrate strong transformational leadership.

Similarly $H 2$, predicting a positive relationship between EI and transformational leadership for managers who are in agreement/poor, was not supported by the regression results. Examination of mean scores for in agreement/poor in Table I once again suggests that this relationship does exist to a limited degree in this study. If EI is predominantly self-awareness, as suggested by Shipper et al. (2003); it makes sense that managers who are in agreement have high levels of overall EI particularly in the areas of self-awareness and interpersonal skill. But as these managers agree with their subordinates that their leadership skill is lacking, it would imply that these managers struggle in the execution of their leadership behaviors. Perhaps these managers are early in their tenure and thus lack the experience to effectively wield transformational leadership behaviors. A general trend emerged throughout the regression analysis indicating a positive, though not statistically significant for in agreement/poor, relationship between tenure and leadership effectiveness. Perhaps these managers are lacking in the adaptability component of EI and are unable to alter their leader behaviors as is required by the situation. It would be interesting to examine more closely the impact of management experience in future research to better delineate this relationship.

H3, which posited a positive relationship between EI and overestimation of leadership ability, was not supported. Here, Table I suggests that the opposite may 
hold true, which is consistent with past research results (Sosik and Megerian, 1999). Drawing on Yammarino and Atwater (1997) and the hypothesis development of Sosik and Megerian (1999), our research results affirm past research that indicates overestimators tend to possess high levels of self-monitoring as well as self-awareness, which are both related to EI (Goleman, 1995), and have been linked to inflated self-ratings (Tunnell, 1980).

An alternative explanation may lie in our study method. Consistent with the preponderance of EI research, we relied on self-evaluations of manager EI. Managers who overestimate their leadership skill tend to focus on the other-oriented aspect of self-awareness, which parallels Goffman's (1959) concept of dramaturgy or self-presentation. It is reasonable to expect that managers who are concerned with self-presentation will inflate their self-ratings of leadership as found in the current study as well as previous research (Atwater and Yammarino, 1997; Sosik and Megerian, 1999). However, it follows that leaders who inflate their self-ratings of leadership skill for the sake of public appearances may similarly inflate self-ratings of EI. Thus, the negative relationship suggested by Table I between EI and subordinate ratings of leadership for overestimators may be due to common source bias. This study design threat seems particularly salient for overestimators, as they are intuitively more susceptible to social desirability in keeping with their preoccupation with self-presentation. In fact, Sosik and Megerian (1999) found that overestimators' focus on self-presentation results in higher leader evaluations from their superiors. Thus, it may be useful to collect subordinate ratings of manager EI in addition to transformational leadership to address this potential methodological weakness.

H4 predicted that EI would be positively related to subordinate assessments of leadership skill for underestimators. Although this hypothesis was only partially supported by the regression results in Table III, our results in Table I supported this relationship. In fact, underestimators received significantly higher ratings from subordinates than did managers in any other category of agreement. Table III illustrates that the strongest and most significant relationship exists for the interpersonal subscale and leadership skill, suggesting that underestimators tend to be more self-aware and this self-awareness is linked to higher-levels of follower ratings. At first glance, this finding may be puzzling. Research suggests that the underestimated self ratings of underestimators are based on excessive modesty, low self-worth, and emotional instability (Sosik and Megerian, 1999; Yammarino and Atwater, 1997). Perhaps, the deflated self-ratings in this study are more a function of social-desirability or political factors. That is, in an organization with a culture that discourages self-promotion, it would be reasonable to expect that managers would be more likely to distort their self-ratings in a downward direction. This may have an impact on the self-ratings of EI for underestimators as well and further warrant incorporating subordinate ratings of manager EI in future research. However, research (Van Velsor et al., 1993) indicates that underestimators tend to receive the highest subordinate ratings of self-awareness as well as leadership effectiveness. If we adopt the viewpoint of Godshalk and Sosik (2000) of the critical self-evaluation, humility, and self-sacrifice of underestimators, it stands to reason that underestimators make excellent candidates for transformational leaders. It may be that the self-ratings of leadership skill are deflated by the modesty and humility of underestimators, while 
their energy is more outward focused for the benefit of their subordinates and the overall organization, resulting in higher actual leader performance. Because this finding is somewhat counterintuitive, it may be especially interesting to examine the relationship between modesty, EI, and transformational leadership. Recent research (Lee and Ashton, 2004, 2006) indicates that the Five-Factor Model of personality (Costa and McCrae, 1992) is deficient in neglecting this important dimension of personality. The modesty aspect of leadership is particularly understudied in Western management but is more commonly valued in Eastern cultures (Lee and Ashton, 2004).

The meager and sometimes contradictory support for the hypotheses of this study begs the question: Do EI and self-awareness in managers improve their leadership performance? It would appear based on the results of this study that the answer is, sometimes. However, as alluded to in the above discussion, this answer is tempered somewhat by elements of the social context of performance appraisal which are influential in the process of soliciting the self and other ratings at the heart of this study. It would seem that the weaknesses of this research provide sound advice for future researchers in this area. First, it may be prudent to change to an ability-based measure of EI in keeping with the empirical work of Mayer and Salovey (1993). Past research has shown ability-based measures to have more construct validity than mixed-models, which can lead to more accurate empirical findings (Livingstone and Day, 2005). Second, future research should incorporate both subordinate and self-assessments of EI into the study design. At a minimum, measures of manager modesty (Lee and Ashton, 2004, 2006), management experience, perceptions of organizational culture, and social desirability should be incorporated into the survey.

While this study is essentially an extension of Sosik and Megerian (1999) and does not include personality measures, there is considerable discussion in the literature about the potential overlap between personality and EI. For example, O'Connor and Little (2003) found significant correlations between the EQI and Extraversion, Anxiety, and Independence, and a significant correlation between the MSCEIT and Anxiety. They concluded the EQI is measuring personality traits while the MSCEIT is not. Law et al. (2004) concluded that while it is correlated with them, EI is distinct from the Big Five personality dimensions. As suggested above, using ability-based measures as well as measures from multiple stakeholders may yield more meaningful findings. Since ability-based models have shown less overlap with personality dimensions, adopting such measures should avoid confounding EI with personality.

This study also has several strengths which can inform and guide future research. First of all, this was an extension of Sosik and Megerian's (1999) work in that we used a tested and validated measure of EI. Second, this research takes a finer-grain approach by splitting the in agreement category of managers and examining the relationship of EI and subordinate assessments of leadership for both in agreement/good and in agreement/poor, which provided interesting insight into the possibility of high self-awareness coexisting with leader skill deficiencies. Finally, this research is multi-source and tested on a large, matched sample.

This research suggests implications for business practitioners as well. Since Goleman's (1995) earlier work, business media has embraced the concept and potential contributions of EI in the workplace. It is hard to dispute that there is an emotional component to leadership and that effective leaders need to acknowledge this 
component to be successful (Dasborough, 2006; George, 2000). However, businesses need to exercise caution when basing selection, promotion, or reward decisions on measurement of EI. There are too many inconsistencies in the measurement of this trait (Antonakis et al., 2009), particularly for mixed-model scales (Mayer et al., 2008), which may be easier to administer and more cost-effective due to their self-report nature. Basing key employee decisions on EI will likely put employers at legal risk for unlawful human resource practices. Although there are multi-rater scales based on the ability model approach available for use, these typically come with a high price tag, both in terms of usage and licensing fees as well as time. Our recommendation to business practitioners is to invest the money in these more expensive scales if the measurement of EI is valuable to the organization. However, it may be a better use of resources to simply provide training on EI to increase awareness of this subject among employees until research is able to provide better measurement tools and more conclusive evidence of the workplace impact of EI.

Unlike EI, the notion of modesty as an effective leadership trait is one that seems to be less embraced by business practitioners. In business, we tend to look for and reward dominance, competence, and self-assuredness in our leaders. However, this research supports previous findings (Sosik and Megerian, 1999) that modesty may be a key component for transformational leaders. This study suggests that it may be time for business practitioners to look for and promote modesty as a valued trait among their leaders in order to maximize organizational effectiveness.

\section{Conclusion}

This research supports the findings of our predecessors (Sosik and Megerian, 1999), illustrating that at least to some degree the relationship between EI and follower assessment of transformational leadership varies across categories of rating agreement for managers. Interestingly, in this study the only significant relationship we observed was between EI and transformational leadership for underestimators. Over the years, this result has become an increasingly common outcome in research of this nature (Moshavi et al., 2003; Sosik and Megerian, 1999, Sosik, 2001, Sosik and Jung, 2003, Sosik et al., 2004). It seems prudent to further test the theoretical explanations that have emerged in these research discussions by incorporating a measure of modesty into future research designs and examining its relationship to transformational leadership. Furthermore, in this study we were not able to conclusively assess the relationship between EI and follower assessment of transformational leadership for overestimators nor either of the in agreement categories. We believe that this may be a function of the psychometric limitations of the mixed-model self-assessment of EI utilized in this study. Our further understanding of the dynamics of EI will be advanced by similar studies employing an ability model of EI generally and the emergence of valid subordinate assessments of EI into future studies specifically. It stands to reason that the impact of self-presentation and social-desirability will equally impact self-ratings of leadership as well as EI. Hence, other-ratings from EI or multi-rater EI scales may necessarily become a standard before we can reach any definitive conclusions as to the relationship between EI and leadership effectiveness and the implications of EI for individual or organizational performance. 


\section{References}

Antonakis, J., Ashkanasy, N.M. and Dasborough, M.T. (2009), "Does leadership need emotional intelligence?”, The Leadership Quarterly, Vol. 20 No. 2, pp. 247-61.

Ashford, S.J. (1989), "Self-assessments in organizations: a literature review and integrative model”, Research in Organizational Behavior, Vol. 11, pp. 133-74.

Ashkanasy, N.M. and Daus, C.S. (2005), "Rumors of the death of emotional intelligence in organizational behavior are vastly exaggerated", Journal of Organizational Behavior, Vol. 26 No. 4, pp. 441-52.

Atwater, L.E. and Yammarino, F.J. (1992), "Does self-other agreement on leadership perceptions moderate the validity of leadership and performance predictions?”, Personnel Psychology, Vol. 45 No. 1, pp. 141-64.

Atwater, L.E. and Yammarino, F.J. (1997), "Self-other rating agreement: a review and model", Research in Personnel and Human Resources Management, Vol. 15, pp. 121-74.

Atwater, L.E., Ostroff, C., Yammarino, F.J. and Fleenor, J.W. (1998), "Self-other agreement: does it really matter?", Personnel Psychology, Vol. 51 No. 3, pp. 577-89.

Atwater, L., Waldman, D., Atwater, D. and Cartier, P. (2000), “An upward feedback field experiment: supervisors' cynicism, reactions, and commitment to subordinates", Personnel Psychology, Vol. 53 No. 2, pp. 275-97.

Avolio, B.J. and Bass, B.M. (1995), Multifactor Leadership Questionnaire: Manual, Forms, and Scoring Key, Mind Garden, Menlo Park, CA.

Bachman, J., Stein, S., Campbell, K. and Sitarenios, G. (2000), "Emotional intelligence in the collection of debt", International Journal of Selection and Assessment, Vol. 8 No. 3, pp. 176-82.

Bar-On, R. (1997), Bar-On Emotional Quotient Inventory: Technical Manual, Multi Health Systems, Toronto.

Bass, B.M. (1985a), Leadership and Performance beyond Expectations, Free Press, New York, NY.

Bass, B.M. (1985b), “Leadership: good, better, best”, Organizational Dynamics, Vol. 13 No. 3, pp. 26-40.

Bass, B.M. (1990), Bass and Stogdill's Handbook of Leadership: A Survey of Theory and Research, Free Press, New York, NY.

Bass, B. (1999), "Two decades of research and development in transformational leadership", European Journal of Work and Organizational Psychology, Vol. 8 No. 1, pp. 9-32.

Bass, B. and Avolio, B. (1990), Transformational Leadership Development: Manual for the Multifactor Leadership Questionnaire, Consulting Psychologists Press, Palo Alto, CA.

Berson, Y. and Sosik, J. (2007), "The relationship between self-other rating agreement and influence tactics and organizational processes", Group \& Organization Management, Vol. 32 No. 6, pp. 675-98.

Bliese, P.D. (1998), "Group size, ICC values, and group-level correlations: a simulation", Organizational Research Methods, Vol. 1 No. 4, pp. 355-73.

Bono, J.E. and Judge, T.A. (2004), "Personality and transformational and transactional leadership: a meta-analysis", Journal of Applied Psychology, Vol. 89 No. 5, pp. 901-11.

Brett, J.F. and Atwater, L.E. (2001), "360 degrees feedback: accuracy, reactions, and perceptions of usefulness", Journal of Applied Psychology, Vol. 86 No. 5, p. 930.

Brown, F.W. and Moshavi, D. (2005), "Transformational leadership and emotional intelligence: a potential pathway for an increased understanding of interpersonal influence", Journal of Organizational Behavior, Vol. 26 No. 7, pp. 1-5. 
Bryman, A. (1996), "Leadership in organizations", in Clegg, S.P., Hardy, C. and Nord, W.R. (Eds), Handbook of Organization Studies, Sage, Thousand Oaks, CA, pp. 276-92.

Burns, J.M. (1978), Leadership, Harper \& Row, New York, NY.

Church, A.H. (1997), "Managerial self-awareness in high-performing individuals in organizations", Journal of Applied Psychology, Vol. 82 No. 2, pp. 281-92.

Ciarrochi, J., Chan, A. and Caput, P. (2000), "A critical evaluation of the emotional intelligence construct”, Personality and Individual Differences, Vol. 28 No. 3, pp. 539-61.

Cleveland, J.N., Vescio, T.K. and Barnes-Farrell, J.L. (2005), in Dipboye, R.L. and Colella, A. (Eds), Discrimination at Work, Lawrence Erlbaum Associates, Mahwah, NJ, pp. 149-76.

Cogliser, C.C., Schriesheim, C.A., Scandura, T.A. and Gardner, W.L. (2009), "Balance in leader and follower perceptions of leader-member exchange: relationships with performance and work attitudes", The Leadership Quarterly, Vol. 20 No. 3, pp. 452-65.

Conte, J.M. (2005), “A review and critique of emotional intelligence measures”, Journal of Organizational Behavior, Vol. 26 No. 4, pp. 433-40.

Costa, P.T. Jr and McCrae, R.R. (1992), NEO Personality Inventory-Revised (NEO-PI-R) and NEO Five-factor Inventory (NEO-FFI) Professional Manual, Psychological Assessment Resources, Odessa, FL.

Cote, S. and Miners, C. (2006), "Emotional intelligence, cognitive intelligence, and job performance", Administrative Science Quarterly, Vol. 51 No. 1, pp. 1-28.

Dasborough, M.T. (2006), "Cognitive asymmetry in employee emotional reactions to leadership behaviors", The Leadership Quarterly, Vol. 17 No. 2, pp. 163-78.

Daus, C. and Ashkanasy, N. (2005), "The case for an ability-based model of emotional intelligence in organizational behavior”, Journal of Organizational Behavior, Vol. 26 No. 4, pp. 453-66.

Dawda, D. and Hart, S.D. (2000), "Assessing emotional intelligence: reliability and validity of the Bar-On Emotional Quotient Inventory (EQ-i) in university students”, Personality and Individual Differences, Vol. 28 No. 4, pp. 797-812.

Der Foo, M., Elfenbein, H.A., Tan, H.H. and Aik, V.C. (2004), "Emotional intelligence and negotiation: the tension between creating and claiming value", The International Journal of Conflict Management, Vol. 15 No. 4, pp. 411-29.

Duehr, E.E. and Bono, J.E. (2006), "Men, women, and managers: are stereotypes finally changing?”, Personnel Psychology, Vol. 59 No. 4, pp. 815-46.

Edwards, J.R. (1993), "Problems with the use of profile similarity indices in the study of congruence in organizational research", Personnel Psychology, Vol. 46 No. 4, pp. 641-65.

Eichinger, R. and Lombardo, M. (2004), "Patterns of rater accuracy in 360-degree feedback", Human Resource Planning, Vol. 27 No. 4, pp. 23-5.

Facteau, C.L. and Facteau, J.D. (1998), "Reactions of leaders to 360-degree feedback from subordinates and peers", Leadership Quarterly, Vol. 9 No. 4, p. 427.

Gardner, W.L., Avolio, B.J., Luthans, F., May, D.R. and Walumbwa, F. (2005), "'Can you see the real me?' a self-based model of authentic leader and follower development", The Leadership Quarterly, Vol. 16 No. 3, pp. 343-72.

George, J.M. (2000), “Emotions and leadership”, Human Relations, Vol. 53 No. 8, pp. 1027-55.

Godshalk, V.M. and Sosik, J.J. (2000), "Does mentor-protégé agreement on mentor leadership behavior influence the quality of a mentoring relationship?", Group \& Organization Management, Vol. 25 No. 3, pp. 291-316.

Goffman, E. (1959), The Presentation of Self in Everyday Life, Doubleday, New York, NY.

Goleman, D. (1995), Emotional Intelligence, Bantam Books, New York, NY. 
Goleman, D. (1998), “What makes a leader?”, Harvard Business Review, Vol. 76 No. 6, pp. 93-102.

Goleman, D., Boyatzis, R. and McKee, A. (2002), Primal Leadership: Realizing the Power of Emotional Intelligence, Harvard Business School Press, Boston, MA.

Gowing, M., O'Leary, B. and Brienza, D. (2006), “A practitioner's research agenda: exploring real-world applications and issues", in Druskat, V., Sala, F. and Mount, F. (Eds), Linking Emotional Intelligence and Performance at Work: Current Research Evidence with Individuals and Groups, Lawrence Erlbaum Associates, Mahwah, NJ, pp. 245-65.

Grimal, N. (1992), A History of Ancient Egypt, Blackwell Publishing, Malden, MA.

Grubb, W.L. and McDaniel, M.A. (2007), "The fakability of Bar-On's emotional quotient inventory short form: catch me if you can”, Human Performance, Vol. 20 No. 1, pp. 43-59.

Ilgen, D.R., Fisher, C.D. and Taylor, M.S. (1979), "Consequences of individual feedback on behavior in organizations”, Journal of Applied Psychology, Vol. 64 No. 4, pp. 349-71.

Jae, J.H. (1997), "Emotional intelligence and cognitive ability as predictors of job performance in the banking sector", unpublished Master's thesis, Ateneo de Manila University, Manila.

James, L.R., Demaree, R.G. and Wolf, G. (1984), "Estimating within-group interrater reliability with and without response bias", Journal of Applied Psychology, Vol. 69 No. 1, pp. 85-98.

Johnson, J. and Ferstl, K.L. (1999), "The effects of interrater and self-other agreement on performance improvement following upward feedback", Personnel Psychology, Vol. 52 No. 2, pp. 271-303.

Judge, T.A. and Piccolo, R.F. (2004), "Transformational and transactional leadership: a meta-analytic test of their relative validity", Journal of Applied Psychology, Vol. 89 No. 5, pp. 755-68.

Kanungo, R.N. and Mendonca, M. (1996), Ethical Dimensions of Leadership, Sage Publications, Thousand Oaks, CA.

Kluger, A.N. and DeNisi, A. (1996), "The effects of feedback interventions on performance: a historical review, a meta-analysis, and a preliminary feedback intervention theory", Psychological Bulletin, Vol. 119 No. 2, pp. 254-84.

Landy, F.J. (2005), "Some historical and scientific issues related to research on emotional intelligence", Journal of Organizational Behavior, Vol. 26 No. 4, pp. 411-24.

Law, K.S., Wong, C. and Song, L.J. (2004), "The construct and criterion validity of emotional intelligence and its potential utility for management studies", Journal of Applied Psychology, Vol. 89 No. 3, pp. 483-96.

LeBreton, J.M. and Senter, J.L. (2008), "Answers to 20 questions about interrater reliability and interrater agreement”, Organizational Research Methods, Vol. 11 No. 4, pp. 815-52.

Lee, K. and Ashton, M.C. (2004), "Psychometric properties of the HEXACO Personality Inventory", Multivariate Behavioral Research, Vol. 39 No. 2, pp. 329-58.

Lee, K. and Ashton, M.C. (2006), "Further assessment of the HEXACO Personality Inventory: two new facet scales and an observer report form", Psychological Assessment, Vol. 18 No. 2, pp. 182-91.

Levy, P.E. and Williams, J.R. (2004), "The social context of performance appraisal: a review and framework for the future", Journal of Management, Vol. 30 No. 6, pp. 881-905.

Livingstone, H. and Day, A. (2005), "Comparing the construct and criterion-related validity of ability-based and mixed-model measures of emotional intelligence", Educational \& Psychological Measurement, Vol. 65 No. 5, pp. 851-73.

Locke, E.A. (2005), "Why emotional intelligence is an invalid concept", Journal of Organizational Behavior, Vol. 26 No. 4, pp. 425-31. 
Lowe, K.B., Kroeck, K.G. and Sivasubramaniam, N. (1996), "Effectiveness correlates of transformational and transactional leadership: a meta-analytic review of the MLQ literature", Leadership Quarterly, Vol. 7 No. 3, pp. 385-425.

Luthans, F. and Avolio, B.J. (2003), “Authentic leadership: a positive developmental approach”, in Cameron, K.S., Dutton, J.E. and Quinn, R.E. (Eds), Positive Organizational Scholarship, Berrett-Koehler, San Francisco, CA, pp. 241-61.

Mayer, J., Roberts, R. and Barsade, S. (2008), "Human abilities: emotional intelligence", Annual Review of Psychology, Vol. 59 No. 1, pp. 507-36.

Mayer, J.D. and Salovey, P. (1993), "The intelligence of emotional intelligence”, Intelligence, Vol. 17 No. 4, pp. 433-42.

Mayer, J.D. and Salovey, P. (1997), “What is emotional intelligence?”, in Salovey, P. and Sluyter, D. (Eds), Emotional Development and Emotional Intelligence: Educational Implications, Basic Books, New York, NY.

Mayer, J.D., Salovey, P. and Caruso, D.R. (2000), "Emotional intelligence as Zeitgeist, as personality, and as a mental ability", in Bar-On, R. and Parker, J. (Eds), The Handbook of Emotional Intelligence: Theory, Development, Assessment, and Application at Home, School, and in the Workplace, Jossey-Bass, San Francisco, CA, pp. 92-117.

Moshavi, D., Brown, F.W. and Dodd, N.G. (2003), "Leader self-awareness and its relationship to subordinate attitudes and performance", Leadership \& Organization Journal, Vol. 24 No. 7, pp. 407-18.

O'Connor, R.M. Jr and Little, I.S. (2003), "Revisiting the predictive validity of emotional intelligence: self-report versus ability-based measures", Personality and Individual Differences, Vol. 35 No. 8, pp. 1893-902.

Parker, J.D.A., Summerfeldt, L.J., Hogan, M.J. and Majeski, S.A. (2004), "Emotional intelligence and academic success: examining the transition from high school to university", Personality and Individual Differences, Vol. 36 No. 1, pp. 163-72.

Piaget, J. (1981), Intelligence and Affectivity: Their Relationship during Child Development, Annual Reviews, Palo Alto, CA, translated by Brown, T.A. and Kaegi, C.E. (originally published in 1954).

Podsakoff, P. and Organ, D. (1986), "Self-reports in organizational research: problems and prospects", Journal of Management, Vol. 12 No. 4, pp. 531-44.

Ross, S.M. and Offermann, L.R. (1997), "Transformational leaders: measurement of personality attributes and work group performance”, Personality and Social Psychology Bulletin, Vol. 23 No. 10 , pp. 1078-86.

Salovey, P. and Mayer, J. (1990), "Emotional intelligence", Imagination, Cognition, and Personality, Vol. 9 No. 3, pp. 185-211.

Shipper, F., Kincaid, J., Rotondo, D.M. and Hoffman, R.C. (2003), “A cross-cultural exploratory study of the linkage between emotional intelligence and managerial effectiveness", International Journal of Organizational Analysis, Vol. 11 No. 3, pp. 171-91.

Sosik, J. (2001), "Self-other agreement on charismatic leadership: relationships with work attitudes and managerial performance", Group \& Organization Management, Vol. 26 No. 4, pp. 484-511.

Sosik, J. and Megerian, L. (1999), “Understanding leader emotional intelligence and performance: the role of self-other agreement on transformational leadership perceptions", Group \& Organization Management, Vol. 24 No. 3, pp. 367-90.

Sosik, J.H. and Godshalk, V.M. (2004), "Self-other rating agreement in mentoring", Group \& Organization Management, Vol. 29 No. 4, pp. 442-69. 
Sosik, J.J. and Jung, D.I. (2003), "Impression management strategies and performance in information technology consulting: the role of self-other rating agreement on charismatic leadership", Management Communications Quarterly, Vol. 17 No. 2, pp. 233-68.

Sosik, J.J., Godshalk, V.M. and Yammarino, F.J. (2004), “Transformational leadership, learning goal orientation, and expectations for career success in mentor-protégé relationships: a multiple levels of analysis perspective", The Leadership Quarterly, Vol. 15 No. 2, pp. 241-61.

Stroh, L.K., Brett, J.M. and Reilly, A.H. (1992), "All the right stuff: a comparison of female and male managers' career progression”, The Journal of Applied Psychology, Vol. 77 No. 3, pp. 251-60.

Thorndyke, R.L. and Stein, S. (1937), "An evaluation of the attempts to measure social intelligence”, Psychological Bulletin, Vol. 34 No. 5, pp. 275-84.

Tunnell, G. (1980), "Intra-individual consistency in personality assessment: the effect of self-monitoring”, Journal of Personality, Vol. 48 No. 2, pp. 220-32.

Van Velsor, E., Taylor, S. and Leslie, J.B. (1993), “An examination of the relationships among self-perception accuracy, self-awareness, gender, and leader effectiveness", Human Resource Management, Vol. 32 Nos 2/3, pp. 249-63.

Waldman, D.A. and Bowen, D.E. (1998), “The acceptability of 360 degree appraisals: a customer-supplier relationship perspective", Human Resource Management, Vol. 37 No. 2, pp. 117-29.

Wechsler, D. (1940), "Non-intellective factors in general intelligence", Psychological Bulletin, Vol. 37 No. 1, pp. 444-5.

Wegner, D. and Vallacher, R. (1980), The Self in Social Psychology, Oxford University Press, New York, NY.

Wicklund, R. (1979), "The influence of self on human behavior”, American Scientist, Vol. 67 No. 2, pp. $187-93$.

Wong, C.S. and Law, K.S. (2002), "The effect of leader and follower emotional intelligence on performance and attitude: an exploratory study", The Leadership Quarterly, Vol. 13 No. 3, pp. 243-74.

Yammarino, F.J. and Atwater, L.W. (1997), "Do managers see themselves as others see them? Implications of self-other rating agreement for human resources management", Organizational Dynamics, Vol. 25 No. 4, pp. 35-44.

Young, M. and Dulewicz, V. (2007), "Relationships between emotional and congruent self-awareness and performance in the British Royal Navy", Journal of Managerial Psychology, Vol. 22 No. 5, pp. 465-78. 